\title{
LA LEGÍTIMA DEFENSA. ¿ES IMPRECISA LA CARTA DE LAS NACIONES UNIDAS O INTERPRETACIONES AMAÑADAS LA DEFORMAN? ¿ES LA DEFENSA PREVENTIVA CONTRA EL TERRORISMO UNA NORMA IN STATU NASCENDI?
}

\begin{abstract}
SUMARIO: I. Reflexiones sobre el artículo de José B. Acosta Estévez "La operación Libertad Duradera y la legítima defensa a la luz de los atentados del 11 de septiembre de 2001". II. Introducción. III. La administración Clinton y la operación Alcance Infinito. IV. Una fecha que vivirá en la infamia: martes 11 de septiembre de 2001. V. La reacción del Consejo de Seguridad. Las resoluciones 1368 (2001) y 1373 (2001). VI. La administración Bush y la operación Libertad Duradera. VII. El marco jurídico de la legítima defensa, los atentados del 11 de septiembre y la respuesta estadounidense. VIII. La solución "correcta" del conflicto afgano. IX. La legítima defensa preventiva como doctrina estratégica de seguridad. X. El tránsito del multilateralismo autoritario al unilateralismo agresivo. XI. Consideraciones finales.
\end{abstract}

José Luis VALLARTA MARRÓN*

\section{REFLEXIONES SOBRE EL ARTÍCULO DE JOSÉ B. ACOSTA ESTÉVEZ "LA OPERACIÓN LIBERTAD DURADERA Y LA LEGÍTIMA DEFENSA A LA LUZ DE LOS ATENTADOS DEL 11 DE SEPTIEMBRE DE 2001"}

En el volumen VI, de 2006, del Anuario Mexicano de Derecho Internacional del Instituto de Investigaciones Jurídicas de la UNAM, se publicó un artículo del profesor José B. Acosta Estévez, titulado "La operación libertad duradera y la legítima defensa a la luz de los atentados del 11 de septiembre de 2001". El artículo da lugar a muchas reflexiones que pueden aclarar algunas ideas y plantear o confirmar las dudas que, salvo

* Maestro de derecho internacional público en la Facultad de Derecho de la UNAM. Embajador de México, jubilado. 
contadas excepciones, presentan necesariamente los textos jurídicos negociados, incapaces de dar siempre una respuesta única y correcta.

El propósito de este trabajo es reflexionar junto con el profesor español sobre los temas por él tratados en busca de coincidencias y divergencias que tal vez sirvan para contribuir a la doctrina, útil como actividad académica. Sigamos pues la estructura del artículo comentado con la esperanza de que del diálogo salgan resultados positivos.

Tenemos la firme convicción de que el derecho internacional, especialmente el contenido en la Carta de las Naciones Unidas (ONU) tiene un contenido justo, y mecanismos e instituciones que usados de buena fe permiten a los Estados la indispensable lucha contra el terrorismo, dentro del marco de la ley. El derecho no es estático y habrá de evolucionar con el mundo, pero hoy el derecho internacional ofrece medios e instrumentos para la defensa de los Estados contra el terrorismo sin necesidad de interpretar de manera deformante la institución de la legítima defensa.

Cuando el Consejo de Seguridad de la ONU adoptó por unanimidad la resolución 1368 (2001), nos pareció que la referencia en un párrafo del preámbulo al derecho inmanente a la legítima defensa individual o colectiva estaba fuera de lugar, porque en ese caso ya no procedía autodefensa alguna sino la acción por el Consejo de Seguridad. De momento no nos pareció que la referencia a la legítima defensa tuviera la maquiavélica intención de aducir posteriormente que todo lo que hicieran Estados Unidos de América (EUA) y sus aliados después del 11 de septiembre, como reacción a los ataques sufridos en Nueva York y en Washington, se presentaría a la comunidad internacional como actos de legítima defensa. Nos pareció que la secuela de acontecimientos estaba muy lejos de encajar en el supuesto jurídico y en las consecuencias previstas en el artículo 51 de la Carta de la ONU en el que se reconoció y acotó la institución de la legítima defensa surgida del derecho consuetudinario.

Veamos cómo percibe este asunto un catedrático español, frecuente colaborador del Anuario Mexicano de Derecho Internacional.

\section{INTRODUCCIÓN}

En el artículo comentado, se menciona que, después del 11 de septiembre, algo ha empezado a cambiar en el modo de afrontar la lucha contra el terrorismo desde el derecho internacional; ojalá se afrontara desde el derecho internacional que ofrece posibilidades de acción que 
contrastan con algunas de las acciones militares emprendidas por Estados Unidos de América y el Reino Unido, concebidas y ejecutadas al margen del derecho. Cierto es que el ataque a las torres gemelas del World Trade Center de Nueva York y al Departamento de Defensa de los Estados Unidos de América (EUA) es condenable y ha recibido un repudio al cual nos unimos sin titubeos; no obstante, creemos que es injusto denunciar ese ataque como si fuera el más grave acto de barbarie sufrido por víctimas inocentes o como si hubiera tenido una magnitud tal que lo singularice como el más perverso acto de nuestros tiempos. Las guerras internacionales no se suspendieron con la prohibición del uso de la fuerza armada, incorporada en la Carta de las Naciones Unidas, y el Estado víctima de los ataques del 11 de septiembre es responsable de violaciones aún más graves al derecho internacional, incluida la invasión a Irak de marzo de 2003, para mencionar una de tantas. No diremos que EUA mereció el ataque terrorista, no, nadie lo merece; tal crimen no se hubiera justificado ni contra el régimen de la Alemania nazi, pues un ataque terrorista a la población civil jamás puede justificarse. Tan sólo deseamos poner el evento en su perspectiva correcta y no señalarlo como el único o más reprobable acto de nuestros tiempos.

Recordemos algunas de las guerras y conflictos bélicos librados desde 1945; empecemos con las bombas atómicas en Hiroshima y Nagasaki, lanzadas poco después de firmada la carta de la ONU, sin que estuviera en peligro la sobrevivencia de EUA y sin que fuera un último recurso o el único medio para derrotar a Japón (requisitos que posteriormente puso la Corte Internacional de Justicia en una histórica opinión consultiva para que el uso de esas armas fuera legítimo, dentro de las excepciones previstas en la Carta de la ONU a la prohibición general del uso de la fuerza). ${ }^{1}$

Veamos una relación de guerras contra movimientos de liberación nacional: Francia/Viet-Nam, 1945-54; Indonesia/Países Bajos, 1945/49; Francia/Túnez, 1952-56; Francia/Marruecos, 1953-56; Francia/Argelia, 1954-62; Reino Unido/Chipre, 1955-59; Indonesia/Países Bajos, 1960-62; Portugal/Angola, 1961-74; Portugal/Guinea-Bissau, 1961-74; India/Portugal, 1961; Reino Unido/Yemen del Sur, 1963-67; Portugal/Mozambique, 1964-74. 
Sigamos ahora con una relación de adquisiciones territoriales o intentos de conquista mediante el uso de la fuerza: República Popular de China/Tibet, 1950; Sahara Occidental, 1973; Indonesia/Timor del Este, 1975-83; Somalia/Etiopía, 1975-88; Irán/Irak, 1980-88; Argentina/Reino Unido, 1982; Irak/Kuwait, 1990-91.

Consideremos guerras o conflictos para cambiar gobiernos de otro Estado: EUA/Guatemala, 1954; Unión Soviética/Hungría, 1956; EUA/ Cuba, 1961; EUA/República Dominicana, 1965; Unión Soviética y aliados/Checoslovaquia, 1967; Tanzania/Uganda, 1978-89; Viet-Nam/Kampuchea, 1978-89; Francia/Imperio Centro Africano, 1979; Unión Soviética/Afganistán, 1987-89; EUA, Honduras, Argentina/Nicaragua 1981-88; India/Sri Lanka, 1983-90; EUA/Grenada, 1983; EUA/Panamá, 1989; OTAN/Yugoslavia, 1999; EUA, Reino Unido, Australia/Irak, 2003. ${ }^{2}$

Inexplicablemente, el autor de las listas transcritas (mencionado infra nota 2) seguramente por su posición política, omitió en su relación de conflictos la cruenta guerra de Vietnam en la que Vietnam del Sur, con el apoyo y participación bélica de EUA, se enfrentó con su poderoso aliado a Vietnam del Norte, que percibía el conflicto como una guerra civil en la que EUA ilegalmente apoyaba a una de las facciones. Igualmente, ese autor omite los constantes conflictos y guerras que Israel ha provocado y sufrido con sus vecinos.

Regresemos al tema principal de este artículo, o sea el análisis junto con el profesor Acosta Estévez de los eventos post-11 de septiembre. Salta a la vista la afirmación del ilustre profesor español en el sentido de que el Consejo de Seguridad se automarginó porque el uso de la fuerza contra Afganistán se hizo, no en el marco del artículo 42 de la Carta de la ONU, sino por vía de la legítima defensa. Notamos una contradicción, pues en el mismo artículo el autor hace un atinado análisis de la legítima defensa en el que claramente indica que esa añeja institución, surgida como derecho consuetudinario, reconocida y acotada por la Carta de la ONU, no da base jurídica para una respuesta armada que no sea inmediata y que tenga por fin un acto punitivo o preventivo, ajeno a la necesidad de repeler un ataque. Es cierto que el Consejo de Seguridad, órgano polí-

2 Véase Weisburd, Mark, A., "Consistency, universality and the customary law of interstate force", Customary International Law on the Use of Force, editado por Enzo Cannizzaro y Paolo Palchetti, Leiden-Boston, Mauritius Nijhoff Publishers, 2005, pp. $31-77$. 
tico que no dice el derecho a la manera de un órgano judicial, incluyó en el preámbulo de la resolución 1368 (2001) un desafortunado párrafo, causante de ambigüedades y confusiones, en el que se reconoció el derecho inmanente a la legítima defensa individual o colectiva de conformidad con la Carta de las Naciones Unidas, irrelevante, según nosotros, para este caso.

Más adelante comentaremos el acertado análisis que el autor ibérico hace del marco jurídico de la legítima defensa; por ahora preguntémonos si, en la eventualidad de que el Consejo de Seguridad no hubiera podido aprobar por algún veto la resolución 1368 (2001) en la que instó a los Estados a que colaboraran con urgencia para someter a la acción de la justicia a los autores de esos ataques terroristas, ¿hubiera sido conforme a derecho la invasión de Afganistán? Si la respuesta es negativa quiere decir que el artículo 51 de la Carta de la ONU no da base para una acción militar ex post facto como la emprendida en Afganistán por EUA y aliados. ¿Puede entonces encontrarse la legalidad de esa invasión en la resolución 1368 (2001) del Consejo de Seguridad que instó a los Estados a colaborar para llevar a la justicia a los autores, organizadores y patrocinadores del crimen del 11 de septiembre y expresó su disposición para responder a esos ataques terroristas?

Creemos que hubiera sido mejor que el Consejo de Seguridad, actuando en el marco del capítulo VII de la Carta de la ONU, hubiera autorizado expresa y categóricamente el uso de la fuerza por los Estados miembros para los fines mencionados en la resolución aprobada, máxime que todo parecía indicar que el régimen de los talibanes había incurrido en un auténtico terrorismo de Estado por su tolerancia o complicidad con el ataque del 11 de septiembre. No obstante, también creemos que la resolución citada da alguna base jurídica, no invocada por los invasores, para sostener que el uso de la fuerza en Afganistán fue autorizado por el Consejo de Seguridad, dándose así el supuesto jurídico de una de las excepciones a la prohibición del uso de la fuerza, es decir, la autorización por el Consejo de Seguridad. Puesto que los Estados miembros de la ONU no pusieron a la disposición del Consejo de Seguridad fuerzas armadas que permitieran a ese órgano usar la fuerza, como se planeó en San Francisco; en la práctica, el Consejo, a falta de ejércitos, aplica el artículo 42 de la Carta mediante autorizaciones para que los Estados adop- 
ten las medidas militares coercitivas previstas en esa disposición $;{ }^{3}$ luego entonces, puede decirse, ciertamente con una interpretación muy libre y a la luz del repudio que se expresó en la ONU y por la comunidad internacional al cobarde ataque del 11 de septiembre, que la acción militar en Afganistán se hizo con base en ese artículo 42 y no en el 51 relativo a la legítima defensa, a pesar de que los actores no hayan seguido ese discurso argumentativo.

El autor del artículo comentado dice:

Pero la objeción que cabe oponer a la acción militar estadounidense como supuesto de ejercicio de legítima defensa, es que la reacción frente a los atentados no fue inminente [iinmediata?] ni el Consejo de Seguridad adoptó nunca las medidas previstas en el artículo 42 de la Carta. Por consiguiente, la cuestión a responder es si, frente a los actos terroristas perpetrados el 11 de septiembre, la respuesta de los Estados Unidos de América fue adecuada ¿Se enmarca la intervención militar estadounidense en el ámbito del derecho de legítima defensa o, por el contrario, se trata de una acción propia de la denominada legítima defensa preventiva? ${ }^{4}$

Es cierto que, al no haber sido una acción inmediata sino diferida, la acción analizada no tiene una de las características que la doctrina y el sentido común exigen a la legítima defensa, pero, ¿por qué el profesor Acosta Estévez nos dice que la objeción para catalogar la acción militar como legítima defensa, además de la cuestión del momento de la operación, radica en el hecho de que el Consejo de Seguridad no adoptó las medidas previstas en el artículo 42 de la Carta?, ¿con qué base entonces instó a los Estados a someter a la justicia a los autores, organizadores y patrocinadores de los ataques terroristas del 11 de septiembre, a sabiendas de que para tal fin parecía indispensable el uso de la fuerza contra Al Qaeda y contra el gobierno de los talibanes, si como era de temerse, no procedería ese gobierno a la extradición? Entendemos que al referirse a "la denominada" legítima defensa preventiva, el catedrático español no está apoyando esa institución inexistente en el derecho internacional.

3 Véase Cassese, Antonio, Internacional Law, Nueva York, Oxford University Press, 2001, pp. 296 y 297 (casos en que el Consejo de Seguridad de la ONU ha autorizado el uso de la fuerza por Estados miembros).

4 Véase Acosta Estévez, José B., "La operación Libertad Duradera y la legítima defensa a la luz de los atentados del 11 de septiembre de 2001", Anuario Mexicano de Derecho Internacional, vol. VI, 2006, p. 16. 
Dos cuestiones hay que dilucidar: primero, por qué la referencia al artículo 42, si esta disposición no tiene relevancia alguna para el funcionamiento de la legítima defensa hasta la etapa, si ésta llega, en que el Consejo de Seguridad adopta las medidas que suspenden el ejercicio del derecho a la legítima defensa para sustituir esa medida de auto-protección por la acción armada del Consejo de Seguridad. En segundo término, creemos que es válido decir, aun cuando tal discurso no haya sido usado por EUA y aliados, que cuando el Consejo de Seguridad en la resolución 1368 (2001) instó a los Estados a colaborar para someter a la justicia a los autores del ataque estaba autorizando, con los términos ambiguos propios de textos negociados entre posiciones diversas, toda clase de medidas incluida una acción militar limitada al propósito expreso de someter a la justicia a los presuntos autores del crimen contra EUA.

Recordemos que no se pone en duda la legalidad de la intervención militar en Kuwait para sacar a Irak del Estado invadido en violación de la Carta de la ONU. Recordemos también los términos de la autorización del Consejo de Seguridad expresados en la resolución 678 (1990), del 29 de septiembre de ese año sobre la invasión de Kuwait, y veremos que no se autoriza expresamente el uso de la fuerza armada:

\section{El Consejo de Seguridad,}

2. Autoriza a los Estados miembros que cooperen con el Gobierno de Kuwait para que, a menos de que el Iraq cumpla plenamente para el 15 de enero de 1991 o antes las resoluciones que anteceden, como se indica en el párrafo 1 supra, [entre ellas la 660 en la que se condenó la invasión y se exigió el retiro de las tropas iraquíes] utilicen todos los medios necesarios para hacer valer y llevar a la práctica la resolución $660^{5}$ y todas las resoluciones pertinentes aprobadas ulteriormente y para restablecer la paz y la seguridad internacionales en la región.

Reconocemos que hay diferencia en los términos de las citadas resoluciones sobre Kuwait y sobre el 11 de septiembre, pero a la vez reiteramos que en ninguna de ellas se autorizó expresamente el uso de la fuerza armada. Luego entonces, afirmamos que si se buscan razones para justificar en derecho la acción militar en Afganistán, el necesariamente difícil y escabroso discurso argumentativo debería basarse, en todo caso, en la 
ambigua resolución del Consejo de Seguridad y no en la institución de la legítima defensa. Insistimos, si no se hubiera aprobado la resolución 1368 (2001), la acción militar en Afganistán hubiera sido una represalia armada, acción militar declarada ilegal por la Asamblea General de la ONU en la Declaración sobre los Principios de Derecho Internacional referentes a las relaciones de amistad y a la cooperación entre los Estados de conformidad con la Carta de las Naciones Unidas, aprobada mediante la resolución 2625 (XXV) de esa Asamblea. En ese supuesto, la acción militar contra el gobierno de los talibanes hubiera podido clasificarse como acción punitiva o preventiva, que ningún Estado tiene el derecho de llevar a cabo sin previa y expresa autorización del Consejo de Seguridad de la ONU, so pena de cometer una agresión armada. Recordemos que el Consejo de Seguridad sí tiene atribuciones para autorizar medidas preventivas o punitivas.

Ahora bien, EUA no ha utilizado el argumento de la implícita autorización del Consejo de Seguridad para usar la fuerza para capturar a Osama Bin Laden y cómplices, sino que ha intentado justificar la invasión de Afganistán en el derecho a la legítima defensa. Si como creemos, junto con el profesor Acosta Estévez, que la invasión de Afganistán no puede justificarse como un caso de legítima defensa por no cumplir con el requisito temporal de ser una reacción inmediata para rechazar una agresión, y si nuestro titubeante intento de ver en la resolución del Consejo de Seguridad una ambigua autorización para usar todo medio para llevar a la justicia a los autores de los crímenes del 11 de septiembre, no es aceptable, entonces tenemos que concluir que la invasión de Afganistán fue ilegal y violatoria de la Carta de la ONU, a pesar de que el Consejo de Seguridad haya legalizado ex post facto la ocupación y los eventos que siguieron a esa invasión.

La invasión de Afganistán se inició el 7 de octubre de 2001, 26 días después del 11 de septiembre. La justificación intentada por EUA y su principal aliado, el Reino Unido, ha sido la legítima defensa en anticipación a futuros ataques. Ambos Estados informaron al Consejo de Seguridad sobre sus acciones, invocando el artículo 51 de la Carta y aduciendo que el objetivo de sus acciones era prevenir y desalentar futuros ataques. ${ }^{6}$

6 Véase la nota del 7 de octubre del representante permanente de EUA en la ONU, dirigida al presidente del Consejo de Seguridad; puede consultarse en http.//www.un. int/usa/s-2001-946.htm, en la que se declara: "In response to these attacks, and in accor- 
Difícilmente podemos imaginar una mayor adulteración del artículo invocado.

No han faltado autores que han destacado la unidad sin precedentes que, en apoyo de EUA, siguió al artero ataque del 11 de septiembre; muchos gobiernos expresaron enfáticamente rechazo a la agresión; otros permitieron el uso de su espacio aéreo para la operación contra Afganistán, o bien ofrecieron apoyo logístico; inclusive Estados islámicos, en este contexto, condenaron el terrorismo y ofrecieron condolencias a EUA. ${ }^{7}$

Esa situación nos hace considerar la siguiente hipótesis: EUA hubiera podido lograr una resolución del Consejo de Seguridad que, por lo menos, hubiera utilizado un lenguaje similar al de la resolución que autorizó el uso de la fuerza en Kuwait contra Irak (resolución 678 (1990), del 29 de septiembre de ese año), pero prefirió una que hiciera una inapropiada referencia al derecho a la legítima defensa para poder llevar adelante su política sobre seguridad internacional y su pretendido derecho a la defensa preventiva.

Sabemos que el artículo 51 de la Carta de la ONU plantea problemas de interpretación, ${ }^{8}$ pero llevarlo al extremo de suprimir los requisitos: a) De la inmediatez de la reacción militar de la víctima, y b) El del propósito del rechazo a la agresión sufrida, tal como lo han hecho EUA y Reino Unido con su inadmisible tesis de la defensa preventiva, es interpretar los términos de la Carta para llevar el sentido a nociones que no están incorporadas en el texto de la Carta ni corresponden al espíritu de la misma. Nos negamos a reconocer que los ataques del 11 de septiembre y las resoluciones del Consejo de Seguridad hayan dado lugar a normas in statu nascendi. Nos negamos a reconocer que por una inapropiada referencia en un párrafo del preámbulo a la legítima defensa, el Consejo de Seguridad haya dado carta blanca a EUA y al Reino Unido para tomar las medidas que estimen necesarias para defenderse preventivamente de otra organizaciones o de otros Estados.

dance with the inherent right of individual and collective self-defence, United Status armed forces have iniciated actions designed to prevent and deter further attack on the United States... We may find that our self-defence requires further actions with respect to other organizations and other States".

7 Véase Duffy, Hellen, The "War on Terror" and the Framework of International Law, Nueva York, Cambridge University Press, 2003, pp. 186-197.

8 Véase Vallarta Marrón, José Luis, Derecho internacional público, México, Porrúa-UNAM, Facultad de Derecho, 2006, pp. 335-338. 
En el Consejo de Seguridad, los miembros no permanentes pueden desempeñar un papel para evitar que algunos miembros permanentes promuevan resoluciones tramposas que den pie a ulteriores acciones violatorias de la Carta de la ONU como la resolución comentada, pretextando autorizaciones continuas o acciones unilaterales no autorizadas en apoyo a esas resoluciones. Esperemos que la planeada reforma a la Carta de la ONU y la ampliación del Consejo de Seguridad permita a los miembros no permanentes una acción colectiva de mutuo apoyo que frene los ímpetus bélicos de algunos miembros permanentes.

Somos conscientes de que el derecho internacional surgió en Europa como un derecho consuetudinario que reconocía a los Estados soberanos la facultad de hacer la guerra en defensa de sus intereses nacionales, sin más limitaciones que las que fueron surgiendo en el derecho humanitario para limitar los medios de hacer la guerra y brindar protección a la población civil. Es obvio que, en aquel entonces, en esa era pre ONU, el derecho a la legítima defensa procedía ante cualquier amenaza, pues si el soberano era libre de usar la fuerza armada a su libre arbitrio, con mayor razón lo era para supuestamente defenderse en cualquier circunstancia.

Cuando la Carta de la ONU reconoció el derecho inmanente a la legítima defensa, lo acotó al caso de ataque armado y, en cuanto al ámbito de aplicación temporal, lo limitó desde que se sufre el ataque armado hasta que el Consejo de Seguridad adopta medidas efectivas. La doctrina y el sentido común también han limitado ese derecho a una reacción que debe ser inmediata y que debe tener como fin único rechazar la agresión.

No han faltado autores que han pretendido interpretar la Carta de la ONU como si el artículo 51 de la misma hubiera conservado el derecho a la legítima defensa como existió antaño, sin otra cortapisa que la opinión del gobierno que supuestamente se defiende. ${ }^{9}$ Lo grave es que esa amañada interpretación ha sido la esgrimida por EUA y Reino Unido para actuar en Afganistán, reservándose el "derecho" de actuar militarmente contra otras organizaciones terroristas o contra otros Estados. ${ }^{10}$ Nos preguntamos qué queda de la prohibición al uso de la fuerza por los Estados consagrada en la Carta de San Francisco; felizmente, conforme pasa el

9 Véase McDougal, Myers S., "The Soviet-Cuban quarantine and Self Defence", International Law in the Twentieth Century, Nueva York, Appteton-Century-Crofts, The American Society on International Law, 1963, pp. 597-604.

10 Véase supra nota 1. 
tiempo, la intervención en Afganistán se observa con mayor objetividad y menos emoción y se confirma que las violaciones a la Carta de la ONU no tienen valor derogatorio y que sus disposiciones se mantienen vigentes.

\section{LA ADMINISTRACIÓN CLINTON Y LA OPERACIÓN ALCANCE INFINITO}

Se nos dice en el artículo comentado, que en la cuestión tratada interacciona lo político y lo jurídico. De acuerdo, así el analista político que expone razones políticas olvidándose del deber ser incurre en faltas éticas, en tanto que el jurista que ignora las rezones políticas se coloca fuera de la realidad. Veamos si el catedrático, con quien dialogamos en este trabajo, narra el acontecer político cumpliendo con el deber de todo jurista de denunciar la ilegalidad de posiciones políticas y acciones incompatibles con las normas jurídicas aplicables o si se limita a una tarea descriptiva.

Al describir las acciones y dichos de autoridades estadounidenses y británicas, occidentales y pertenecientes al "mundo civilizado", encontramos una ausencia de denuncia frente a reivindicaciones para llevar a cabo represalias y otros actos al margen del derecho internacional. Según se nos narra en ese artículo, Clinton habló de represalias y elaboró un plan con el nombre de Delenda est para acabar con Al Qaeda; ${ }^{11}$ por otra parte, Albright se refirió a:

Nuestros ataques de represalia con misiles en agosto de $1998 \ldots$ una cuestión que se ha planteado es por qué no invadimos sin más Afganistán, derrocamos a los talibanes y dispersamos a Al Qaeda en su propio terreno. Habría habido razones para justificar la acción militar pero, sin el tremendo impacto del 11 de septiembre, la invasión de Afganistán no la habría tolerado la mayoría de los ciudadanos. Y habría sido condenada por las comunidades árabes e islámicas del mundo entero. ${ }^{12}$

Pregunto al lector si, con base en la afirmación del profesor Acosta Estévez, en el sentido de que "en la cuestión tratada se interacciona lo

11 Véase Acosta Estévez, op. cit., nota 4, pp. 18-20.

12 Ibidem, pp. 19 у 21. 
político y lo jurídico", hubiera sido adecuado que, en un artículo destinado a un anuario de derecho internacional, se hubiera expresado la ilegalidad de toda represalia armada y se hubiera denunciado, con mayor énfasis, el desdén con que las autoridades citadas ignoran the rule of law incorporado en la Carta de la ONU. Hubiéramos preferido que un catedrático de derecho internacional hubiera hecho, en el contexto de sus atinadas descripciones, una equiparación entre una represalia armada unilateral y un acto terrorista, ambos actos ilegales, con consecuencias funestas análogas para víctimas civiles inocentes.

\section{UNA FECHA QUE VIVIRÁ EN LA INFAMIA: MARTES 11 DE SEPTIEMBRE DE 2001}

Ya lo hemos dicho, condenamos el infame ataque armado del 11 de septiembre, pero no lo califiquemos como el más infame de la historia; las guerras relámpago de Hitler, el holocausto, el ataque a Pearl Harbor, la bombas atómicas en Hiroshima y Nagasaki, los horrores de la guerra en Vietnam, el bombardeo de Guernica o las víctimas civiles en Irak, a partir de marzo de 2003, y otros crímenes vivirán en la infamia. No obstante, sí tenemos que reconocerlo como un hito en la historia, no porque haya sido el más artero y cruel ataque sufrido por la humanidad, sino porque hirió al gigante estadounidense en su territorio y provocó una reacción que ha llevado a EUA a actuar al margen del derecho internacional.

\section{LA REACCIÓN DEL CONSEJO DE SEGURIDAD. LAS RESOLUCIONES 1368 (2001) Y 1337 (2001)}

Se afirma en el artículo comentado que: "Los atentados terroristas perpetrados en Nueva York y Washington el 11 de septiembre del 2001, marcan un punto de inflexión tanto en la lucha internacional contra el terrorismo como en la figura de la legítima defensa". ${ }^{13}$ Creemos que la institución de la legítima defensa se mantiene tal como se enuncia en el artículo 51 de la Carta de la ONU, como un derecho inmanente de los Estados que, conforme a derecho, sólo puede ejercerse en caso de ataque 
armado (o inminencia de un ataque ya en progreso), y que, como la doctrina y el sentido común lo han precisado, haciendo una correcta analogía con el derecho de las personas físicas a la legítima defensa, ésta tiene que ser inmediata, proporcional y debe tener como único fin rechazar el ataque o la agresión.

Desafortunadamente, no han faltado internacionalistas que únicamente limitan el derecho a la legítima defensa al estado de necesidad y a la proporcionalidad, ignorando olímpicamente los requisitos de la inmediatez y el de fin u objetivo de esa autodefensa. ${ }^{14}$ Con ese criterio, las represalias armadas y la legítima defensa son lo mismo.

En este punto, nos parece pertinente hacer una comparación. Nuevamente, supongamos que el Consejo de Seguridad no hubiera aprobado la resolución 1368 (2001) y que EUA hubiera procedido con la acción militar en Afganistán, ¿se habría cumplido con el requisito de la inmediatez, de la proporcionalidad y del único fin lícito de la legítima defensa: el rechazo del ataque armado? Creemos que no, por lo menos en lo que se refiere al requisito temporal y al de la finalidad, no se cumplieron, por tanto, el ataque a los talibanes hubiera sido una represalia preventiva y punitiva unilateral y violatoria del derecho internacional, por no encajar en ninguna de las excepciones a la prohibición del uso de la fuerza. También se ha planteado la cuestión de si procede la legítima defensa frente al ataque de un agresor que no sea un Estado. Por nuestra parte no vemos problema. Por ejemplo, si bandas armadas irregulares controlan parte del territorio de un Estado y desde allí lanzan un ataque, el Estado víctima tiene todo el derecho de defenderse, como si el ataque fuera de un ejército regular, con las mismas limitaciones que hemos señalado a la institución de la autodefensa. En cuanto a la integridad territorial del Estado desde donde operan las bandas armadas irregulares de nuestro ejemplo, la falta de control por el Estado de dónde procede el ataque, justificaría la acción de legítima defensa en su territorio. Si el Estado desde donde operan las bandas armadas irregulares tolera o permite el ataque, el mismo sería imputable al Estado que las aloja e incurriría en responsabilidad. ${ }^{15}$ Creemos que esta opinión es compatible con la de la Corte Inter-

14 Véase Duffy, op. cit., nota 7, p. 188.

15 Véase artículo 80. del proyecto de artículos sobre la responsabilidad del Estado por hechos internacionalmente ilícitos (resolución 56/83 de la Asamblea General de la ONU). 
nacional de Justicia que limita el alcance del artículo 51 de la Carta de la ONU al caso del ataque de un Estado a otro Estado, si se comprueba la complicidad, franca tolerancia o incapacidad del Estado que aloja a los terroristas. ${ }^{16}$

Desde luego, en el caso de Afganistán queda la duda de si el gobierno de los talibanes ejercía control sobre Al Qaeda; menos duda queda sobre la tolerancia que puede basarse en la negativa para extraditar a Osama Bin Laden y otros sospechosos de haber sido autores intelectuales del ataque del 11 de septiembre.

Otro problema que tenemos que resolver, si descartamos, como lo hacemos, a la legítima defensa como la base jurídica de la invasión de Afganistán es que el uso de la fuerza ha ido mucho más allá del fin de la resolución... concebida para llevar a la justicia a los autores del crimen del 11 de septiembre. El derrocamiento de un gobierno con base en esa resolución, sería llevar la interpretación de la misma a extremos inadmisibles; por tanto, la visión retrospectiva que ahora tenemos es que la invasión de Afganistán y su secuela de acontecimientos, que no pueden justificarse como legítima defensa, tampoco puede justificarse con la citada resolución. Otra cosa hubiera sido si la operación militar hubiera tenido éxito en lo relativo a la captura de Osama Bin Laden y cómplices, y si logrado ese objetivo las fuerzas de ocupación se hubieran retirado, pero ni fueron eficientes para la captura de los presuntos delincuentes, ni se interesaron por obtener una autorización; prefirieron una resolución que les facilitara interpretar el artículo 51 de la Carta de la ONU a su antojo.

Consideremos otra ficción. Supongamos que un vuelo de la aerolínea X sale de la ciudad de México con destino a Montreal, Canadá, y que estando todavía sobrevolando territorio mexicano, unos terroristas se apoderan de la aeronave y no responden a cuestionamiento alguno de autoridades mexicanas ni estadounidenses; supongamos que EUA tiene información de sus servicios de inteligencia y razones para temer que la intención es usar la aeronave a la manera del 11 de septiembre. ¿Tendrían las fuerzas armadas de EUA el derecho a la legítima defensa para derribar la aeronave en zona despoblada en territorio estadounidense? Creemos que sí, dejando a un lado la difícil cuestión de si la intención de

16 Véase Legal Consequences of the Construction of a Wall in the Occupied Palestinian Territory, Advisory Opinion, ICJ, 9 de julio de 2004, parágrafo 139. 
los secuestradores era distinta a la supuesta por las autoridades de EUA. Con este ejemplo queremos destacar la diferencia entre el supuesto derecho a la legítima defensa semanas después del 11 de septiembre y un caso ficción en el que quedaría claro el supuesto jurídico del artículo 51 de la Carta de la ONU, a pesar de que el ataque no provenga de otro Estado y de que se utilice como arma una aeronave civil.

Se cita en el artículo del profesor Acosta Estévez a un autor ${ }^{17}$ que afirma que: "la evolución de los acontecimientos volvió a poner de manifiesto la debilidad de esta organización internacional cuando el Consejo de Seguridad no asume el papel institucional que le otorga la carta y deja la respuesta en manos del Estado lesionado, quien actúa sin ningún tipo de control internacional".

La cita hace referencia al caso de Kosovo en el que el Consejo de Seguridad no autorizó la intervención de la OTAN, dejando a la operación militar de esa organización en la ilegalidad, con el atenuante de los fines humanitarios de la misma. Aclaremos, cuando el Consejo de Seguridad no autoriza una acción militar, ese Consejo no "deja la respuesta en manos del Estado lesionado", lo desautoriza para actuar militarmente y reafirma la prohibición del uso de la fuerza incorporada en el artículo 2o., párrafo 4 de la Carta de la ONU; lo que sucede es que muchos gobiernos no aceptan el Estado de derecho y actúan según sus intereses nacionales, no siempre legítimos, con una mentalidad pre-ONU y retrocediendo a la época en que era lícito para los Estados hacer justicia por su propia mano.

Vemos con agrado que el autor comentado menciona que la resolución 1368 (2001) del Consejo de Seguridad de la ONU, no reconoció en concreto el derecho a la auto-defensa a Estados Unidos de América, pues afirma que la resolución recuerda, en términos generales, el derecho inmanente de legítima defensa individual o colectiva de conformidad con la carta; por otra parte, afirma que el Consejo de Seguridad no autorizó el uso de la fuerza contra Afganistán. De ser correcta esa interpretación, la invasión de Afganistán 26 días después del 11 de septiembre, fue ilegal. Insistimos en que la legalidad de la citada invasión pudiera defenderse con un silogismo jurídico en el que la premisa mayor o normativa expresara que el Consejo de Seguridad instó a colaborar para someter a la justicia a los autores de los ataques terroristas; la menor o fáctica, descri- 
biera la invasión, y la conclusión sostuviera la tesis de que la invasión fue legal por el llamamiento del Consejo de Seguridad para actuar. Claro está que las premisas citadas distan mucho de ser axiomáticas y que las afirmaciones en ellas contenidas son opiniones sujetas a demostración. Además está la cuestión de la proporcionalidad, pues si como ya dijimos, el haber llevado la acción al derrocamiento del gobierno de los talibanes nos inclina a unirnos al profesor Acosta Estévez, quien afirma categóricamente que el Consejo de Seguridad no autorizó el uso de la fuerza. Nosotros diríamos que el Consejo de Seguridad no autorizó el uso de la fuerza más allá del necesario para llevar a la justicia a los autores de los crímenes del 11 de septiembre, y que la pretendida defensa preventiva no puede justificarse en los términos generales de la inapropiada referencia en los términos generales de la resolución 1368 (2001).

\section{LA ADMINISTRACIÓN BUSH Y LA OPERACIÓN LIBERTAD DURADERA}

No deja de repugnar, a quienes creemos en el derecho internacional incorporado en la Carta de la ONU, la serie de propuestas y amenazas que el artículo estudiado relata, presentadas y proferidas por diversas autoridades estadounidenses, al margen de toda consideración jurídica. No dudamos que el autor de ese artículo se encuentre entre quienes creemos que la conducta de los Estados debe regirse por el derecho internacional, tan sólo extrañamos la ausencia de una denuncia expresa del carácter antijurídico y amoral de esas proposiciones, al momento de recordarlas.

Por ejemplo, en el artículo se narra cuando el secretario Rumnsfeld, después de que el presidente Bush afirmó: "no haremos distinciones entre los terroristas que han cometido los crímenes y quienes les han ayudado", le hizo ver "que el derecho internacional sólo permitía el uso de la fuerza para evitar futuros ataques y no como castigo", a lo que el mandatario estadounidense respondió: "No, no me importa lo que diga el derecho internacional; alguien va a enterarse de lo que es bueno". ${ }^{18}$

Nuevamente creemos que es una omisión que merece subsanarse; que en un artículo para un anuario jurídico en el que se reproducen tales comentarios debe denunciarse expresa y enfáticamente su incompatibili- 
dad con un régimen de derecho. No sólo los escalofriantes extremos de un jefe de Estado que declara: "No, no me importa lo que diga el derecho internacional...", sino también la controvertida afirmación de Rumnsfeld, quien asegura, según esa versión, "que el derecho internacional sólo permitía el uso de la fuerza para evitar futuros ataques y no como castigo". Ya hemos dicho que el uso de la fuerza para evitar ataques sería conforme a derecho si, y sólo si, el ataque es inminente, si está ya en progreso, o si lo autoriza el Consejo de Seguridad. Nos queda la duda: ¿Debemos interpretar el silencio del profesor Acosta Estévez como una aceptación del supuesto derecho de defensa preventiva, a que aduce Rumsfeld? Veremos si la lectura del artículo nos aclara la duda.

\section{EL MARCO JURÍDICO DE LA LEGÍTIMA DEFENSA, LOS ATENTADOS DEL 11 DE SEPTIEMBRE Y LA RESPUESTA ESTADOUNIDENSE}

Nos recuerda el autor que EUA y el Reino Unido informaron al Consejo de Seguridad de la operación Libertad Duradera "bajo la cobertura del derecho inmanente de legítima defensa reconocido en el artículo 51 de la Carta de la ONU"; prosigue el catedrático con una docta y ortodoxa explicación en la que descarta la llamada legítima defensa preventiva como una institución aceptada en derecho internacional; destaca también que el artículo 51 de la Carta de la ONU fue concebido en 1945 pensando en ataques de un Estado a otro; finalmente, con una exageración que no compartimos, insiste en que tras el 11 de septiembre se ha constatado que en el siglo XXI las amenazas a la seguridad no pueden definirse exclusivamente en términos de Estados. Cierto es que la reacción de EUA y de otros gobiernos marcó a esa fecha como el inicio de una guerra muy especial y con métodos de dudosa legalidad contra el terrorismo, y que un país con sucesivos gobiernos belicosos por primera vez se vio atacado en su territorio, pero un vistazo a los actos terroristas en la historia universal, nos permite comprobar que ni los talibanes ni Osama Bin Laden inventaron esa forma de lucha armada ni por primera vez en la historia la seguridad se ve afectada por ese tipo de lucha.

Analiza el profesor Acosta Estévez la cuestión de si los actos terroristas del 11 de septiembre fueron ataques armados y nos recuerda que el Consejo de Seguridad calificó ese trágico evento como "ataque", sin calificarlo de "armado". Es justo analizar esa cuestión, pero de entrada nos parece que, con independencia de si se usan o no armas regulares o de si 
quien ataca es o no oficial de un gobierno, el 11 de septiembre fue un ataque armado. El problema que enfrentó EUA para encajar su respuesta en la institución de la legítima defensa prevista en la Carta de la ONU es el mismo que ha tenido Israel para presentarnos sus represalias unilaterales, punitivas y con fines de prevención, como actos de legítima defensa. No negamos que un Estado sienta la necesidad de adoptar medidas punitivas o preventivas como respuesta al terrorismo, tan sólo las condicionamos a una previa y expresa autorización del Consejo de Seguridad, de otra manera retrocedemos al derecho internacional anterior a la ONU y al Pacto Briand-Kellog.

Cuando se debatió en la ONU la conveniencia de definir la agresión, los Estados occidentales pusieron en duda la utilidad de esa definición sobre la base de que, según el artículo 39 de la Carta de la ONU, corresponde al Consejo de Seguridad determinar la existencia de toda amenaza a la paz, quebrantamiento de la paz o acto de agresión; por tal motivo, la definición de la agresión contenida en la resolución 3314 (XXIX) de la Asamblea General de la organización mundial, fue concebida como "lineamientos" de esa Asamblea al Consejo de Seguridad y como una lista no exhaustiva a la que el citado Consejo puede agregar otros actos no mencionados por el órgano plenario de la ONU. ${ }^{19}$

Creemos que el hecho de que el Consejo de Seguridad haya omitido el vocablo "armado" después de referirse a los hechos del 11 de septiembre es irrelevante. Aún aceptando - y creemos que es objetivo hacerloque los hechos del 11 de septiembre fueron el "ataque armado" previsto en el artículo 51 de la Carta de San Francisco; no obstante, la reacción de la víctima por las razones que ya hemos señalado no fue en legítima defensa.

La comparación con la legítima defensa, que en derecho interno tienen las personas físicas, arroja luz, y la analogía es buena lógica en este caso: si un sujeto es víctima de un intento de robo a mano armada y logra herir o matar al atacante, la inmediatez de su reacción, la proporcionalidad de la misma y su fin de rechazar la agresión, le permitiría aducir legítima defensa, pero si el mismo sujeto es herido y robado, a nadie se le ocurriría decir que esa víctima tendría, con base en la institución de la legítima defensa, derecho de organizarse y atacar y matar al que lo agredió

19 El autor del presente artículo representó a México en el Comité que definió la agresión. 
días o semanas después del incidente. ¿Por qué se insiste entonces en aducir, respecto del 11 de septiembre, que no habiendo ya ataque que rechazar por la consumación del mismo, se tiene derecho a la legítima defensa semanas después? ¿Por qué no se acepta que sólo el Consejo de Seguridad tiene la atribución de autorizar toda acción punitiva o preventiva, si los Estados voluntariamente crearon ese sistema de seguridad internacional?

Después de analizar la definición de la agresión de la Asamblea General de la ONU, el profesor Acosta Estévez, parafraseando esa definición, nos dice:

Las fuerzas armadas de Afganistán ni invadieron ni ocuparon ni bombardearon el territorio de los Estados Unidos de América, ni a sus fuerzas armadas terrestres, navales o aéreas; esto es al adoptar el Consejo de Seguridad las resoluciones 1368 (2001) y 1373 (2001) no sólo no establece una conexión entre los atentados terroristas y un Estado determinado (Afganistán), sino que tampoco identifica a los Estados interesados respecto del reconocido derecho inmanente a la legítima defensa. ${ }^{20}$

Que el Consejo de Seguridad no haya determinado la responsabilidad del gobierno de los talibanes no libera de responsabilidad al derrocado gobierno si toleró esos actos o fue cómplice. En el proyecto de artículos sobre responsabilidad internacional de los Estados por hechos ilícitos de la Comisión de Derecho Internacional de la ONU, se reconoce, en el artículo 8o., que todo hecho ejecutado por instrucciones o bajo la dirección o el control del Estado es imputable al Estado. ${ }^{21}$ Las evidencias producidas antes y después de la invasión sobre la tolerancia del gobierno de los talibanes, que el profesor Acosta Estévez documenta en su artículo, pudieran ser suficientes para declarar la responsabilidad internacional de ese gobierno por los actos del 11 de septiembre. En lo que no estamos de acuerdo es en la afirmación del catedrático español, quien sostiene que, de probarse una participación sustancial del gobierno de los talibanes en el ataque del 11 de septiembre, "el derecho a la legítima defensa de los Estados Unidos de América ha sido utilizado en buena lid". ${ }^{22}$ Tenemos que repetirnos y pedimos disculpas al lector por ello, pero aún

21 Véase resolución 56/82 de la Asamblea General de la ONU.

22 Véase Acosta Estévez, op. cit., nota 4, p. 40. 
comprobada la participación sustancial del gobierno de los talibanes, la invasión de Afganistán no fue el acto de legítima defensa reconocido en la Carta de la ONU.

Encontramos contradicciones en el artículo analizado; según lo parafraseado en el párrafo anterior, parece que el autor reconoce que, probada la participación sustancial del gobierno de los talibanes, EUA ejerció una legítima defensa al invadir Afganistán, pero acto seguido, expone de manera muy ortodoxa, y podemos agregar irrefutable, la ya consolidada doctrina sobre los requisitos o condiciones de la legítima defensa, a saber: respuesta inmediata, necesaria, proporcional y encaminada a repeler un ataque en curso; al respecto concluye que en la respuesta armada no concurrió la condición de inmediatez. ¿Será que la expresión "el derecho a la legítima defensa de los Estados Unidos de América ha sido utilizado en buena lid", es tan sólo una expresión literaria en una lengua que el autor domina con brillo, pero sin intención de someterla a un rigor jurídico y doctrinario?

El catedrático español nos lleva en su bien documentado artículo al análisis del carácter provisional que, según entendemos, él considera característica esencial de todo acto de legítima defensa ejercido de conformidad con el artículo 51 de la Carta de la ONU. En la Carta de San Francisco - que ahora percibimos como un sueño idealista que raya en lo ingenuo - se concibió al Consejo de Seguridad como un órgano eficiente que habría de tomar cartas en todo caso de legítima defensa para sustituir con medidas efectivas al Estado o Estados que ejercieran esa auto-protección inmediata. La realidad nos muestra que ante la parálisis del Consejo de Seguridad, por un uso irresponsable del veto, los actos de legítima defensa son provisionales, porque la extensión de los mismos a perpetuidad sería un abuso una vez rechazada la agresión, no porque el Consejo de Seguridad tenga que actuar como condición para que la legítima defensa sea conforme a derecho; es decir, la parálisis del Consejo de Seguridad para tomar las medidas previstas en el artículo 51 de la Carta de la ONU, no afectaría el derecho a continuar con las medidas esenciales para esa defensa. Cabe aclarar que esa extensión en el tiempo de la legítima defensa no autoriza anexiones ni administraciones de territorios ocupados a la manera israelí; más bien autorizaría una legítima defensa o legítima resistencia contra objetivos militares en los territorios ocupados, pues toda ocupación ilegal es un acto de agresión, aún cuando se haya iniciado en una operación de legítima defensa. 
Felizmente, en beneficio de la comprensión del pensamiento del profesor Acosta Estévez, en su artículo incluye la siguiente cita de Remiro Brotóns, que entendemos él comparte:

La legítima defensa se justifica, dentro de un sistema de seguridad colectiva, por el hecho de que el ataque armado, la agresión, está en curso y ha de atajarse en tanto las instituciones comunes toman las medidas pertinentes. Esta circunstancia no se produce habitualmente en los actos terroristas. Reaccionar frente a ellos utilizando la fuerza en el país que los alberga, sin autorización del Consejo de Seguridad, puede ser un acto de represalia, no de legítima defensa. Pero las represalias armadas son también incompatibles con las obligaciones de los miembros de la ONU. ${ }^{23}$

Insiste el profesor Acosta Estévez en que el Consejo de Seguridad no actuó en el marco del artículo 42 de la Carta de la ONU, que le da atribuciones para hacer uso de la fuerza armada cuando las medidas adoptadas por ese órgano principal, que no impliquen el uso de la fuerza armada, puedan ser inadecuadas o han probado serlo. Tal afirmación, aunada al reconocimiento de que la invasión de Afganistán no fue un acto de legítima defensa, lleva necesariamente a la conclusión de que tal operación fue ilegal y, por tanto, un acto de agresión. Cita el catedrático español una carta de EUA al presidente del Consejo de Seguridad en la que las autoridades de ese Estado afirmaron: "todavía es mucho lo que no conocemos... y podemos encontrarnos con que nuestra legítima defensa requiera nuevas acciones contra otras organizaciones y otros Estados". ${ }^{24}$

Para no incurrir en un silencio indebido frente a tales desatinos, denunciamos esa interpretación de la legítima defensa como contraria al derecho internacional incorporado en la Carta de la ONU, a la ética y a las reglas de interpretación acordadas en la Convención de Viena sobre el Derecho de los Tratados, que obligan a interpretarlos de buena fe, conforme el sentido corriente que haya de atribuirse a los términos del tratado, en el contexto de éstos y teniendo en cuenta su objeto y fin.

Pasa el autor a analizar una tesis necesariamente controvertida, la de la llamada "defensa preventiva" en cuyo marco coloca la invasión de Afga-

23 Véase Remiro Brótons, Antonio, "Estados Unidos no se pregunta en qué se equivoca", $P E$, 2002, núm. 85, p. 119; citado por Acosta Estévez, op. cit., nota 4, p. 45.

24 Doc. S/2001/1946, de 7 de octubre, citado por Acosta Estévez, op. cit., nota 4, p. 46. 
nistán, a pesar de que duda de la conformidad de esa auto-defensa con la Carta de la ONU; nos dice que esa tesis pareció contar con el apoyo del Consejo de la OTAN y de la Unión Europea, y ve en esa circunstancia una tendencia a admitir como lex specialis una norma consuetudinaria que autorizaría una defensa preventiva, no reconocida en la Carta de la ONU; y se pregunta si ¿se está ante una práctica capaz de generar una norma in statu nascendi, en atención a la cual se podría invocar la legítima defensa sin necesidad de la existencia de un ataque armado?25

El derecho internacional público nació como consuetudinario, y se formó desde el siglo XVI con el nacimiento de los grandes Estados europeos; por tanto, fue en sus primeras etapas una práctica de Estados europeos, aceptada como derecho por la opinio iuris de esos Estados. Tal parece que los europeos sienten nostalgia por las remotas épocas en que su opinio iuris era suficiente para la creación del derecho internacional consuetudinario; pero la sociedad internacional ha dejado de ser occidental y homogénea para pasar a ser global o mundial y heterogénea; por tanto, la opinio iuris de las llamadas "naciones civilizadas" occidentales ya no basta para la consolidación del derecho internacional consuetudinario y, sin duda alguna, estamos muy lejos de contar con la opinio iuris mundial que se requiere para la formación de un derecho internacional consuetudinario que reconozca la espuria defensa preventiva antiterrorista que algunos europeos ven subjetivamente como una norma in statu nascendi. La opinión de la OTAN o de la Unión Europea es importante pero no suficiente para impulsar el nacimiento de una norma, sobre todo porque esa opinión es contra legem. En el momento actual, es imposible imaginar una opinio iuris de la comunidad internacional de Estados en su conjunto que haga de una práctica — que además muchos consideramos violatoria de la Carta de la ONU - una norma jurídica consuetudinaria obligatoria erga omnes. No concebimos que tal opinio iuris llegue a formarse en el llamado tercer mundo que, además, percibe tal defensa preventiva anti-terrorista como innecesaria, si el Consejo de Seguridad, y en particular los miembros permanentes, cumplen con la responsabilidad que les dio la comunidad internacional en San Francisco, pues ese Consejo, a diferencia de las organizaciones regionales, coaliciones de Estados y Estados individuales, sí tiene atribuciones para tomar medidas preventivas. 
Nos dice el profesor Acosta Estévez que el Consejo de Seguridad aceptó la respuesta armada de EUA como un derecho a la legítima defensa reconocido en las resoluciones 1368 (2001) y 1337 (2001); que el 14 de noviembre de 2001 apoyó "los esfuerzos internacionales encaminados a erradicar el terrorismo, de manera acorde con la Carta de las Naciones Unidas" y que el 20 de diciembre del mismo año acogió complacido "la evolución de los hechos en Afganistán” [resolución 1386 (2001)]. Recordemos que el propio autor, páginas antes, reconoció que la referencia a la "legítima defensa" en un párrafo del preámbulo de la primera resolución del Consejo de Seguridad fue en términos generales y no atribuida a la acción posterior estadounidense que, sostenemos, pudiera considerarse autorizada indirectamente, y en términos ambiguos, con el llamamiento del Consejo de Seguridad para actuar y someter a la justicia a los autores del crimen del 11 de septiembre, si la acción se hubiera limitado a la captura de los presuntos responsables. En cuanto a la afirmación del secretario general Kofi Annan, del 8 de octubre, en el sentido de que el Consejo de Seguridad "reafirmó el derecho inherente a la legítima defensa individual o colectiva de acuerdo con la Carta de las Naciones Unidas" podemos afirmar que la misma, al igual que las manifestaciones ambiguas del Consejo de Seguridad citadas, no son formadoras de una opinio iuris universal ni mucho menos interpretaciones auténticas o judiciales de la Carta, sino opiniones con fuerte carga política. Por tanto, como las premisas enunciadas por el autor son meras opiniones demostrables, no aceptamos la conclusión a que ese catedrático llega cuando afirma que el Consejo de Seguridad reconoció y legalizó la legítima defensa desarrollada por los Estados Unidos de América a través de la operación Libertad Duradera; tal vez se pueda decir que el Consejo de Seguridad legalizó la invasión, pero no como legítima defensa, debido a los términos ambiguos que provocó la referencia a esa institución en un párrafo del preámbulo.

Acosta Estévez ve en las resoluciones del Consejo de Seguridad la legalización de la operación Libertad Duradera como "legítima defensa", pero ve también la desnaturalización de la autoprotección consagrada en el artículo 51 de la Carta de la ONU y "una ampliación del concepto de legítima defensa individual o colectiva para los casos más graves de terrorismo no atribuibles a un Estado". Insistimos, una acción ex post facto no puede ser legítima defensa, pero sí lo sería una acción ex ante facto para rechazar un ataque armado proveniente de un grupo terrorista. El artículo 51 de la Carta de la ONU reconoce el derecho inmanen- 
te a la legítima defensa individual o colectiva en casos de ataque armado sin una limitación expresa al ataque armado "por un Estado contra otro Estado"; por tanto no se desvirtúa ni se desnaturaliza el artículo 51 si se ejerce la legítima defensa en caso de ataque armado, provenga de quien proviniere. Sí se desvirtúa y se desnaturaliza si se confunde con las represalias, como al parecer lo hacen EUA, Israel y Reino Unido.

Para el autor del artículo comentado:

La respuesta estadounidense se ejerció al margen del marco jurídico de la Carta y, por tanto, cabe englobarla en el marco de la llamada legítima defensa preventiva, circunstancia ésta que permite sostener que dicha acción constituye un uso grave de la fuerza contra un tercer Estado, es decir, una represalia armada - contra un Estado que cobija terroristas- que contradice el espíritu y la letra de la Carta de las Naciones Unidas en tanto que viola su artículo $20 .^{26}$

Por nuestra parte reconocemos el valor de esa interpretación, pero así como condenamos en términos inequívocos por ilegal la invasión de Irak por EUA y el Reino Unido ejecutada con la complicidad de otros, ${ }^{27}$ tratándose del caso de Afganistán, a pesar de que no es nuestra vocación defender las acciones militares de las grandes potencias, normalmente ejecutadas al margen de la ley, no nos sentimos en el terreno firme que pisamos al condenar la invasión de Irak de marzo de 2003. En virtud del llamamiento que hizo el Consejo de Seguridad a todos los Estados a colaborar para someter a la acción de la justicia a los autores, organizadores y patrocinadores de esos ataques terroristas, no sin titubeos podemos aceptar que tal acción fue autorizada por el Consejo de Seguridad, lamentablemente en términos equívocos. En esos ambiguos términos puede leerse una autorización para actuar en aplicación del artículo 42 de la Carta de la ONU, no sólo contra Al Qaeda sino también contra el gobierno de los talibanes, si se demuestra su complicidad.

Dedica el profesor Acosta Estévez unos párrafos en un intento por dilucidar algo que ha perturbado a algunos juristas, respecto de la liberación de Kuwait en 1990, esto es, si el uso de la fuerza para forzar a Irak a

26 Ibidem, pp. 50 y 51.

27 Véase Vallarta Marrón, José Luis, "La supuesta legalidad de la reanudación de la guerra en Irak. Réplica a una defensa de la posición de José María Aznar", Anuario Mexicano de Derecho Internacional, vol. VI, 2006, pp. 985-1017. 
salir de Kuwait fue un acto de legítima defensa colectiva en el marco del artículo 51 de la Carta, que no requería la autorización del Consejo de Seguridad, o una acción del Consejo de Seguridad en el marco del artículo 42 de la Carta (resolución 678 del 28 de noviembre de 1990). Creemos que los Estados miembros del Consejo de Seguridad, sobre todo los que estaban dispuestos a apoyar a Kuwait para recuperar la soberanía perdida con la invasión por Irak, optaron por buscar la autorización del Consejo de Seguridad en unos términos que les dejara abierta la posibilidad de actuar militarmente para fines distintos a la recuperación de la soberanía de Kuwait. Para algunos, sólo la argumentación sofista de EUA y del Reino Unido, en su vano intento de justificar ex post facto conforme al derecho la ilegal invasión de Irak, de marzo de 2003, nos hizo caer en la cuenta de que el doble objetivo señalado en la resolución 678, esto es: a) La retirada de las tropas de Irak de Kuwait y b) La pacificación de la región, era una redacción amañada, seguramente hecha ex profeso para dejar abierta la posibilidad de ulteriores intervenciones; los hechos de marzo de 2003 lo comprobaron. Luego entonces, si bien en todo momento existió el derecho subjetivo de asistir a Kuwait militarmente sin la autorización del Consejo de Seguridad, la acción se llevó a cabo bajo la autorización de la resolución 678 (1990), en el marco del artículo 42 de la Carta de la ONU. El catedrático español cuyo artículo analizamos recurre a un compatriota suyo, J. Carrillo Salcedo, para sostener que con la resolución 678 "no se procedió a una aplicación estricta del artículo 42 de la Carta, esto es a la aplicación de medidas colectivas armadas bajo la autoridad del Consejo de Seguridad con la ayuda del Comité de Estado Mayor, sino a una especie de autorización de medidas de legítima defensa colectiva, casi en el marco del artículo 51 de la Carta". ${ }^{28}$

Por nuestra parte, creemos que toda autorización que dé el Consejo de Seguridad a los Estados miembros para emplear la fuerza armada, se hace con base en el artículo 42 de la Carta y que sólo cuando se actúa en legítima defensa, que no requiere la autorización del Consejo de Seguridad, tiene aplicación el artículo 51. Si se prevé en el artículo 53 de la Carta de la ONU que las organizaciones regionales puedan usar la fuerza bajo la autoridad del Consejo de Seguridad, es admisible la interpreta-

28 Véase Carrillo Salcedo, J., "Las Naciones Unidas ante la década de los noventa", Cursos de Derecho Internacional de Vitoria Gaisteiz, Bilbao, 1990, p. 51, citado por Acosta Estévez, op. cit., nota 4, p. 49. 
ción del artículo 42 como una norma que permite al citado Consejo autorizar a un Estado o grupo de Estados para adoptar medidas coercitivas, bajo su autoridad, que impliquen el uso de la fuerza armada.

\section{LA SOLUCIÓN “CORRECTA” DEL CONFLICTO AFGANO}

La solución "correcta" que se nos propone en el artículo comentado está basada en la siguiente opinión de otro jurista español de renombre, la cual compartimos:

La respuesta es fácil. Ese modo de reacción no era otro, a mi entender, que la acción institucional prevista para los casos de amenazas a la paz, quebrantamientos de la paz o actos de agresión en el capítulo VII de la carta. $\mathrm{Y}$ es del todo verosímil que, de la misma manera que los Estados Unidos de América consiguieron la unanimidad de los miembros del Consejo para la adopción de las resoluciones 1368 y 1373 y otras, hubiesen obtenido la misma actitud unánime para la autorización del desencadenamiento de una acción armada. Pero los Estados Unidos de América decidieron orillar y menospreciar una vez más al Consejo de Seguridad; en aras de sus intereses de poder prefirieron el unilateralismo al multilateralismo, lo que ciertamente hace perder autoridad y credibilidad a las Naciones Unidas en su función primera y primordial de mantenimiento de la paz y seguridad internacionales. ${ }^{29}$

\section{LA LEGÍTIMA DEFENSA PREVENTIVA COMO DOCTRINA ESTRATÉGICA DE SEGURIDAD}

Por lo que se refiere a la Estrategia de Seguridad Nacional de los Estados Unidos de América, estamos en total acuerdo con lo expresado en el artículo que comentamos sobre la incompatibilidad entre esa estrategia con el artículo 51 de la Carta de la ONU. No obstante, la siguiente aseveración del profesor Acosta Estévez nos invita a hacer algunas reflexiones: "Así los Estados Unidos de América podrán utilizar la fuerza armada ante el temor de un ataque previsible e inminente, pero que aún no

29 Véase Pastor Ridruejo, José A., Curso de Derecho Internacional Público y organizaciones internacionales, Madrid, 2003, pp. 727 y 728; citado por Acosta Estévez, op. cit., nota 4, pp. 51-52. 
se ha producido, es decir, el ejercicio de la fuerza se realiza con anterioridad a un ataque con el objeto que éste no llegue a producirse". ${ }^{30}$

La lectura de esa estrategia estadounidense deja claro que, siguiendo una práctica y doctrina tradicionales de EUA, común a todas las grandes potencias, la administración Bush se reserva un supuesto derecho de actuar militarmente, según su libre albedrío, cuando tenga sospechas, por remotas que éstas sean, de que un Estado o grupos irregulares planean algo contra la seguridad de lo que arbitrariamente ellos llaman América. En el párrafo transcrito, se interpreta esa agresiva estrategia como una política para actuar ante el temor de un ataque "previsible e inminente"; si el catedrático español hubiera omitido las palabras entrecomilladas, nuestro acuerdo con él sería total. Son muchos los juristas que interpretan el artículo 51 de la Carta de la ONU comprendiendo en la noción "ataque armado" a la inminencia de un ataque ya en progreso. Por ejemplo, puede decirse que cuando Israel en 1967, durante la llamada guerra de los seis días, levantó su aviación y derrotó al ejército de Egipto en la península del Sinaí, actuó en legítima defensa ante la inminencia de un ataque armado contra el territorio israelí, que no sufrió daños. La lectura de la estrategia de la administración de Bush nos indica que van mucho más allá y que están dispuestos a actuar al margen del derecho internacional, incorporado en la Carta de la ONU, ante el remoto e infundado temor de un ataque y, sin pudor alguno, en represalias vengadoras proscritas por la ley internacional.

El gobierno de EUA usa la noción de legítima defensa sin ton ni son; representaba a México en el Consejo Permanente de la Organización de los Estados Americanos el autor del presente artículo, en su carácter de representante alterno, cuando se debatía la situación en América Central en la época del presidente Reagan y sus "contras antisandinistas" que él llamaba freedom fighters. El representante de EUA, un banquero que adolecía de una patológica ignorancia del derecho internacional, declaró que EUA apoyaba a los "contras" en el ejercicio del derecho a la legítima defensa. Desde luego, la delegación de México dejó constancia de que el derecho a la legítima defensa sólo procede en caso de ataque armado. 


\section{EL TRÁNSITO DEL MULTILATERALISMO AUTORITARIO}

\section{AL UNILATERALISMO AGRESIVO}

Podemos suscribir lo que con tino afirma el catedrático español bajo esta sección. No obstante, insistimos en que la equiparación que hace de los casos de Kosovo (1999), Afganistán (2001) e Irak (2003) permite y merece distinciones. La intervención militar en Kosovo fue ilegal al no encajar el caso en una legítima defensa ni en un caso de autorización por el Consejo de Seguridad en el marco del artículo 42 de la Carta de la ONU, pero existen atenuantes por los fines humanitarios perseguidos; ya hemos dicho que nos parece que no podemos descartar la interpretación de que el Consejo de Seguridad autorizó con términos confusos, imprecisos y ambiguos la acción en Afganistán; cuestión aparte es si se abusó de esa autorización, si se ha violado el derecho internacional humanitario aplicable a los conflictos armados o de si la política allí seguida y las operaciones militares han sido correctas; por lo que se refiere a Irak, la violación al derecho internacional es evidente, la defensa del caso está plagada de falacias y mentiras, y la torpeza de la acción está a punto de producir una derrota similar a la que EUA sufrió en Vietnam. ${ }^{31}$

Al sesudo análisis político que hace el catedrático español, agregaríamos una consideración ausente en sus reflexiones; la referencia a ese momento luminoso en que, después del desmantelamiento del imperio soviético, pareció que, al fin, prevalecía en la ONU una ideología común, una identidad de miras, una clara posibilidad de que el Consejo de Seguridad dejara de ser paralizado por el abuso del veto y asumiera sus responsabilidades. Así, cuando Irak invadió a Kuwait, el Consejo de Seguridad autorizó el uso de la fuerza e hizo prevalecer el Estado de derecho al obligar al invasor a retirarse. Pero vino el caso de Kosovo y el veto paralizó de nuevo al Consejo de Seguridad, ante lo cual, la OTAN actuó al margen de la ley; después, la debacle, el uniteralismo en su mayor e infame expresión, la puñalada artera a la ONU cuando Blair y Bush, ignorando la objetiva labor del veraz sueco Hans Blix, jefe de inspectores del Consejo de Seguridad en Irak, y olvidando la altura de miras que Churchill y Roosvelt expresaron en la Carta del Atlántico, invadieron a Irak colocándose en el nivel de agresores y criminales de guerra. 


\section{CONSIDERACIONES FINALES}

De nuevo podemos suscribir las consideraciones finales del catedrático español, salvo nuestra apreciación de que no son equiparables los casos de Afganistán, Kosovo e Irak. Respetamos la decisión del autor comentado de no referirse a la participación del gobierno de José María Aznar en la invasión de Irak y en la ocupación ilegal que siguió a esa agresión, pero no podemos dejar de destacar esa omisión.

Justo cuando este trabajo estaba en proceso de ser escrito, el consejero político de la Embajada de Israel en México escribió un artículo en el que sostiene que las democracias no cuentan con instrumentos jurídicos para defenderse del terrorismo. ${ }^{32}$ Es verdad que si Israel durante la guerra fría hubiera intentado obtener del Consejo de Seguridad autorización para tomar medidas preventivas que implicaran el uso de la fuerza contra terroristas palestinos, tal empeño hubiera sido infructuoso por el uso irresponsable del veto que los Estados concedieron a los miembros permanentes. Pero ahora que tal vez ingenuamente abrigamos la remota esperanza de que los miembros permanentes cumplan con las responsabilidades que la comunidad internacional les confió en San Francisco, en 1945, podemos exigir a Israel, a EUA y a otros Estados víctimas del terrorismo que utilicen los mecanismos de la Carta de la ONU, es decir la autorización del Consejo de Seguridad, en lugar de actuar unilateralmente, pretextando un supuesto "derecho a la legítima defensa preventiva" o el recurso a una norma supuestamente in statu nascendi, que no es otra cosa que una interpretación espuria y contra legem de la Carta de las Naciones Unidas.

EUA y otras grandes potencias continuarán usando el unilateralismo con todo descaro, y nada podemos hacer para remediar esa situación, salvo impedir que con sofismas y artimañas pretendan que esas actuaciones son conforme a derecho; por lo menos desde el medio académico denunciemos la ilegalidad de esas acciones como lo hace el profesor Acosta Estévez.

\section{Arthur Schlesinger afirmó:}

Los USA ( $\mathrm{sic}$ ) son un imperialismo incompetente y de corta vida, una débil imitación de Roma, Inglaterra y Francia. imperios organizados y longevos.

32 Véase Keinan, Lior, "Enfrentamiento democrático contra el terrorismo", Reforma, México, 25 de marzo de 2007, sección internacional, p. 2. 
Los USA son una democracia capaz de corregirse a sí misma.

Los USA son una superpotencia pero no goza de omnipotencia; la fuerza militar no sustituye a los amigos y a los aliados.

Aferrémonos a la esperanza que nos da el ilustre historiador estadounidense y confiemos que la democracia de la superpotencia, que más funciona en el ámbito doméstico que hacia el exterior, junto con las otras democracias que han olvidado sus compromisos internacionales, tenga la capacidad de corregirse que menciona el escritor citado y se suspendan las políticas que han llevado al autonombrado promotor de la democracia a Abu Ghraib y a Guantánamo. ${ }^{33}$

Tomemos en serio a la opinio iuris como elemento formador del derecho internacional consuetudinario, y mantengamos con firmeza que sólo cuando la comunidad internacional en su conjunto, es decir, que cuando todos los grupos regionales que operan en Naciones Unidas consideran una práctica de los Estados como derecho, se da una opinio iuris capaz de formar una costumbre obligatoria. Mientras ello no ocurra, la práctica de los Estados de una sola región y la opinión de los mismos no justifica que esos actos violatorios del derecho internacional, sobre todo cuando violan normas de ius cogens, como lo es la prohibición del uso de la fuerza armada, tenga el carácter de norma in statu nascendi.

33 Citado por Fuentes, Carlos, “Arthur Schlesinger”, Reforma, México, 21 de marzo de 2007, p. 14. 